\title{
Media make AIDS wishes come true
}

\section{A fuss last week about a crop of HIV infections in Birmingham (England) shows British newspapers, but notably the Sunday Times, at their most fickle.}

FALSE prophets are well-known to be immune to reason and are even able to shrug off evidence that their prophecies are false, usually by playing on the wishes of their followers that the truth were otherwise. So it seems to be with the motley crew of British newspapers which, having first heard of Dr Peter Duesberg at the "alternative" conference on AIDS at Amsterdam a month ago (see $\mathrm{Na}$ ture 357,$188 ; 1992$ ), have since embraced his view that the human immunodeficiency virus (HIV) is an epiphenomenon irrelevant to the causation of AIDS and the comforting corollary that people have nothing to fear from heterosexual intercourse, provided that they do not take drugs or otherwise abuse themselves with chemicals.

Various tabloid newspapers have taken up this dangerous litany, but the most surprising convert to Duesberg's cause is the Sunday Times. (For a time, it seemed that its editorially independent stablemate The Times was about to follow suit, but that seems mercifully to have been an aberration; earlier this week, the newspaper was writing about the prospects for a vaccine against HIV based on the use of the pigtail macaque as an animal model of the infection.) Over the past few weeks, the Sunday Times has reported at length on the spurious controversy stirred up by Duesberg, has given him and his supporters a platform from which to declaim and has dealt dismissively with objections from people such as Sir George Calman, Chief Medical Officer at the UK Department of Health.

Why a serious newspaper should be following such a line is anybody's guess. In its time, specifically that of a previous editor, Mr Harold Evans, it won an excellent reputation for investigative reporting. It has also successfully championed important public causes, notably that the drug thalidomide was negligently put on the British market. But it is also known for having begun serializing 'Hitler's diaries' until they were shown to be forged and, more recently, to have bought the serial rights to a book claiming that the marriage of the Prince and Princess of Wales is in trouble, whose publication can only make matters worse.

But the Sunday Times's prophecy on HIV and the likelihood that AIDS will spread heterosexually seemed last week to have been denied by a counter-example from Birmingham, where it emerged that a single male carrier of HIV - a haemophiliac infected by contaminated factor VIII — had in turn infected at least four women partners, one of whom had died of AIDS. (The infor- mation appears originally to have been leaked to the Birmingham Mail by a physician frustrated by the lack of legal restraints on the carrier's activities.)

It would have been interesting to see how the Sunday Times would have squared these reports with its earlier stance on HIV, but in the event, it escaped the dilemma. By last weekend, the tabloid newspapers had worked out that the Birmingham haemophiliac had engaged in anal intercourse with at least three of the four whom he had infected, and the Sunday Times was able to proclaim on its front page that "NEW EVIDENCE CASTS DOUBT ON BIRMINGHAM AIDS SCARE". The implication was that unnatural intercourse was responsible for the Birmingham episode. Really straight heterosexuals might relax.

This really is a shameful way to carry on. Even granted that newspapers seek selfconsistency, there is no justification for putting consistency before correctness in this way. And the plain truth is that there is no justification for the suggestion that the extra hazards of anal intercourse are novel, The most recent evidence to this effect is that published three months ago by the European Study Group on Heterosexual Transmission of HIV, which estimated that the relative risks of HIV transmission (from men to women) by anal and vaginal intercourse are in the ratio 5.1:1.0 (Brit. med. J. 304, 811; 1992).

Earlier estimates of the relative risk are lower. For what it is worth, the European study also showed that the overall risk of transmission from men to women (at 20 per cent) is twice that from women to men. Risk factors (for infection by HIV) other than anal intercourse include intercourse during menstruation and whether one or other partner is in a late stage of AIDS. Because the figures are based on a survey of partnerships lasting, in some cases, for several years, they cannot be directly used to derive the risk that a single act of sexual intercourse will be infective, which epidemiologists will have to continue to estimate by consistency with studies such as this.

None of this is at odds with the proposition (which Duesberg and the Sunday Times have taken to calling the "AIDS hypothesis"), that HIV infection is the precipitating cause of AIDS. On that view, the infective routes are sexual intercourse and direct contamination of the blood by transfusion or injection. Evidently, the chance of infection in a single act of intercourse is small, probably less than the chance of catching influ- enza from an infected partner on a similar occasion. It is no scandal that estimates of the risks are still so uncertain: they can be derived accurately only from a detailed knowledge of the sexual behaviour of infected people, likely to be as reticent as others on that score.

Similarly, there are many other features of the development of AIDS that remain poorly understood. Thus it seems now to be widely accepted that the pathogenesis of AIDS is not yet understood. Infection by HIV does not quickly lead to the infection of each susceptible cell, let alone to their rapid destruction. Instead, immune deficiency may take years to develop. That is why people are looking for mechanisms to account for this prolonged response, auto-immune reactions perhaps. (The mere suggestion last year see Nature 353, 297; 1991 - that such an explanation might get Duesberg off the hook on which he had impaled himself has been wrongly interpreted as support for everything he had been saying.) And who will deny that an understanding of the pathogenesis of AIDS after HIV infection is likely to provide the surest route to therapy?

Not, it seems, the Sunday Times. Why is it so perverse? The charitable explanation is that the newspaper is responding to the deep feelings of those infected with HIV, who understandably rage at the 'death sentence' they have supposedly been given. But there is a wider constituency, that of those who wish that heterosexual intercourse, however unguarded, has been given the relatively clean bill of health it enjoyed in, say, the 1960s. Even the newspaper that shouldered the thalidomide cause should give some thought to the huge responsibility that it is, as on this occasion, wrong.

There have already been other unwelcome responses to the Birmingham affair. The most sinister development is the demand that AIDS should be made a notifiable disease, which would bring into play the legal powers that allow the compulsory tracing of sexual partners (for venereal diseases) and even quarantine - an administrative recipe which would do more harm (by discouraging voluntary testing) than good. And there is the inevitable resurgence of homophobia, made the more vivid by the smug wish-fulfilment that no harm will come to heterosexuals from AIDS because they do only what they have always done, and also behave 'naturally'. Sadly, the novelty is HIV and the prophecy that heterosexuals have nothing to fear from it is false.

John Maddox 